\title{
Multiple urinary calculi caused by primary hyperoxaluria
}

\author{
A C D de Alwis ${ }^{1}$, P U Gamage ${ }^{2}$, S P Jayawardena ${ }^{2}$, K M J C B Dissanayake ${ }^{3}$ \\ Sri Lanka Journal of Child Health, 2006; 35:144-7
}

(Key words: Urinary calculi, primary hyperoxaluria)

\section{Introduction}

Urinary calculi are uncommon in children; accounting for 0.13-0.94 cases per 1000 hospital admissions in the western world ${ }^{1}$. They can occur secondary to urinary tract infection, congenital urological anomalies, inborn errors of metabolism and immobilization. Commonest underlying metabolic abnormality is hypercalciuria. Cystinuria, xanthinuria, primary hyperoxaluria and hyperuricosuria are less common. Although most stones are considered to be 'idiopathic' in origin, it is believed, that this number would decrease if more detailed investigations of these patients are undertaken $^{2}$. We report two cousins with multiple, recurrent urinary calculi due to primary hyperoxaluria.

\section{Case history 1}

A nineteen month old boy from Galenbindunuwewa presented to Anuradhapura General Hospital with failure to thrive since the age of 7 months. He was born at term, weighing $2900 \mathrm{~g}$ to healthy, first degree consanguineous parents. The weight gain was satisfactory, until 7 months of age, since when it gradually started crossing centile lines downwards, despite successful weaning, absence of significant illness or family disturbance. The stools were of normal frequency and consistency while evidence of food allergy was absent. His cousin has undergone bilateral pyelolithotomy for removal of multiple renal calculi at 4 years of age. (See case history 2).

On examination the weight, length and OFC were $7 \mathrm{~kg}, 71 \mathrm{~cm}$ and $44.5 \mathrm{~cm}$ respectively, all below $0.4^{\text {th }}$ centile. He was pale, and blood pressure was 90/60 $\mathrm{mmHg}\left(50^{\text {th }}\right.$ centile $)$. Examination of other systems was normal.

${ }^{1}$ Consultant Paediatrician, General Hospital, Ratnapura; ${ }^{2}$ Registrar, Lady Ridgeway Hospital for Children, Colombo; ${ }^{3}$ Senior House Officer, General Hospital, Anuradhapura.

(Received on 27 April 2006. Accepted on 22 June 2006)
Urine microscopy revealed 100 pus cells per high power field and culture grew Escherichia coli $>10^{5}$ colonies. Ultrasound scan showed a single calculus measuring $5.1 \mathrm{~cm} \times 1.8 \mathrm{~cm}$ in the right and multiple calculi in the left pelvi-calyceal systems. X ray KUB confirmed the calculi in the left kidney, but those on right were obscured by bowel shadows (Figure 1). IVU confirmed the presence of bilateral renal calculi.

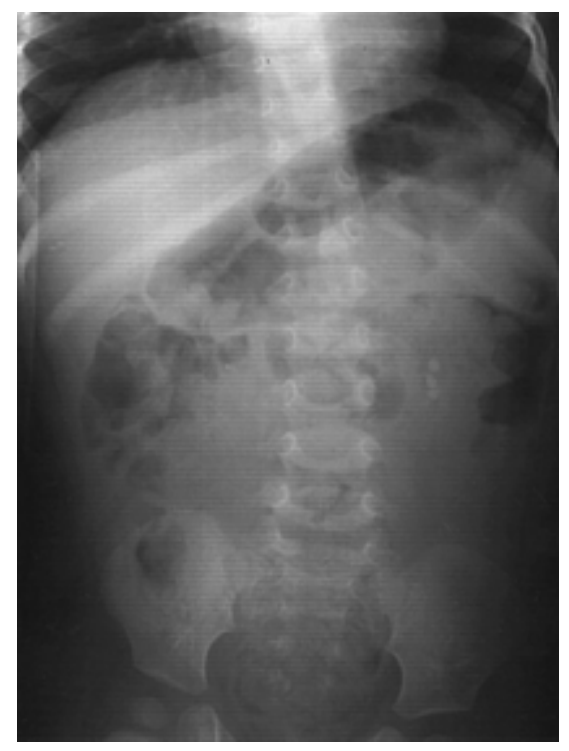

Figure 1 Xray $K U B$

Haemoglobin was $9 \mathrm{~g} / \mathrm{dl}$ with a normochromic normocytic anaemia in blood picture. The results of following investigations were normal; blood urea $3.5 \mathrm{mmol} / \mathrm{L}$, serum creatinine $53 \mathrm{micromol} / \mathrm{L}$, serum sodium $130 \mathrm{mmol} / \mathrm{L}$, potassium $4.5 \mathrm{mmol} / \mathrm{L}$, calcium $2.6 \mathrm{mmol} / \mathrm{L}$, phosphate $1.23 \mathrm{mmol} / \mathrm{L}$, urine calcium excretion $25 \mathrm{micromol} / \mathrm{kg} / 24 \mathrm{hrs}$ (normal up to 100 micromol $/ \mathrm{kg} / 24 \mathrm{hrs}$ ) and urine phosphate excretion 0.4 micromol/ kg/24 hours, arterial $\mathrm{pH} 7.3$ and urinary $\mathrm{pH}$ 6.5. Liver function tests were normal.

Microscopic examination of repeated samples of fresh centrifuged urine for calculogenic material showed an increased amount of calcium oxalate crystals, and urinary excretion of oxalate was 
markedly elevated at $15.4 \mathrm{mmol} / 24$ hours $/ 1.73 \mathrm{~m}^{2}$ (normal value: $<0.5 \mathrm{mmol} / 24 \mathrm{hrs} / 1.73 \mathrm{~m}^{2}$ ). For the above test urine was collected in a container acidified with hydrochloric acid and it was repeated and results were confirmed ${ }^{2}$.

Urolithiasis due to primary hyperoxaluria was diagnosed and he was started on a low oxalate diet and a daily dose of $200 \mathrm{mg}$ of pyridoxine. He also underwent extracorporeal shockwave lithotripsy (ESWL) at Department of Urology of National Hospital, Colombo.

On review at 4 years of age, he was asymptomatic, weighing $11 \mathrm{~kg}\left(50^{\text {th }}\right.$ centile $)$ and measuring $96 \mathrm{~cm}$ $\left(10^{\text {th }}\right.$ centile). Ultrasound scan and $\mathrm{x}$-ray KUB were normal and serum creatinine was $50 \mu \mathrm{mol} / \mathrm{L}$. He continues to be on a low oxalate diet and pyridoxine $200 \mathrm{mg}$ once daily.

\section{Case history 2}

Eleven year old cousin of the above child from Dambulla, presented to Anuradhapura General Hospital with a two month history of weight loss, anorexia and limb pain. She has undergone bilateral pyelolithotomy for removal of calculi at 4 years of age at Kandy Teaching Hospital. Unfortunately she was lost for post-operative follow up.

She was born normally at term weighing $2750 \mathrm{~g}$ to healthy consanguineous parents. On examination she weighed $20 \mathrm{~kg}\left(<3^{\text {rd }}\right.$ centile) and measured $131 \mathrm{~cm}$ $\left(25^{\text {th }}\right.$ centile). She was pale and blood pressure was $100 / 60 \mathrm{~mm} \mathrm{Hg}$. Examination of other systems was normal.

Urine microscopy and culture were normal. Haemoglobin was $5 \mathrm{~g} / 100 \mathrm{ml}$ with normocytic normochromic anaemia in blood picture. X-ray KUB showed multiple calculi in left kidney and distal ureter (Figure 2). Bilateral nephrocalcinosis was seen in ultrasound scan.

Blood urea and serum creatinine were raised being $27 \mathrm{mmol} / \mathrm{L}$ and $660 \mu \mathrm{mol} / \mathrm{L}$. The results of following investigations were normal; serum sodium $135 \mathrm{mmol} / \mathrm{L}$, potassium $4 \mathrm{mmol} / \mathrm{L}, \quad$ calcium $2.5 \mathrm{mmol} / \mathrm{L}$ and phosphate $2.09 \mathrm{mmol} / \mathrm{L}$. Urinary excretion of oxalate was elevated at $17.3 \mathrm{mmol} / 24$ hours/ $1.73 \mathrm{~m}^{2}$.

Chronic renal insufficiency and urolithiasis due to primary hyperoxaluria was diagnosed and she was referred to the urologist and nephrologist. She underwent ESWL at National Hospital, Colombo and end stage renal disease (ESRD) was managed conservatively. Three months later, she developed end stage renal failure and expired.

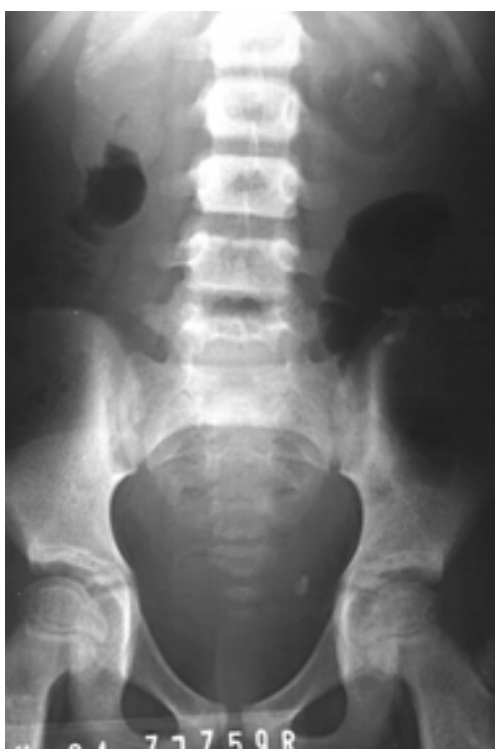

Figure $2 X$-ray $K U B$

\section{Discussion}

The primary hyperoxalurias $(\mathrm{PH})$ are rare, autosomal recessively inherited disorders of oxalate metabolism, which cause excessive endogenous oxalate production. Increased excretion of oxalate leads to saturation of calcium oxalate in urine causing crystal formation, urolithiasis and medullary nephrocalcinosis. Disease progression causes systemic oxalosis with deposition of oxalate in parenchymatous organs, bones and retina.

Two forms of $\mathrm{PH}$ are recognized. Type 1 ( $\mathrm{PH} 1)$, which is relatively more common, has an annual incidence of approximately two to three patients per million and is caused by deficiency of liver-specific peroxisomal enzyme alanine-glyoxylate aminotransferase (AGA), the gene of which, $A G X T$ has been sequenced and located on chromosome $2 \mathrm{q}$ 37.3. PH 1 grossly fits three clinical presentations: (a) a rare infantile form with early nephrocalcinosis and rapid kidney failure; (b) a rare late onset form with stone passage in late adulthood; (c) the most common form with recurrent urolithiasis and progressive renal failure leading to diagnosis of PH 1 in childhood or adolescence $^{3,4}$.

Type 2 ( $\mathrm{PH} \mathrm{2)}$ is rare with only 37 cases being reported and is caused by deficiency of a universal tissue enzyme D-glyceric acid dehydrogenase. 
Patients with PH 2 excrete L-glyceric acid in urine in addition to oxalate. They have a less severe clinical course than $\mathrm{PH} 1$ and their predominant clinical feature is urolithiasis rather than nephrocalcinosis ${ }^{5}$

While our first patient presented with failure to thrive and multiple urinary calculi the second patient had recurrent, multiple urinary calculi, nephrocalcinosis and ESRD. Both were products of first degree consanguineous parents and children themselves were first cousins. Twenty four hour urinary excretion of oxalate was markedly elevated in both. The clinical and laboratory features strongly supported a diagnosis of PH. Non-availability of facilities to assay urinary excretion of glycolate prevented us from describing the type of $\mathrm{PH}$. But, as PH 2 is assumed to be rare, and to have a more benign course, clinical features of our two patients favour a diagnosis of PH 1.

Though PH first present as urolithiasis it can rapidly progress to end-stage renal failure. Hence early diagnosis and treatment is crucial to prevent ESRD. The first steps in treatment include high fluid intake, low oxalate diet and high dose of pyridoxine. Pyridoxine (vitamin $\mathrm{B}_{6}$ ) catalyses AGT and increases its activity. The dosage varies from $20-600 \mathrm{mg}$ /day and therapeutic success can be seen when oxalate excretion decreases. Our first patient was started on this treatment and good clinical response was seen after two years.

Supportive treatment with sodium or potassium citrate and orthophosphate; which are potent inhibitors of calcium oxalate is suggested in the literature $^{3-4}$, and we are planning to start potassium citrate in our patient.

The urological treatment of children with obstructive stone disease is still being debated, and the current therapeutic strategy is minimally invasive procedures like ESWL because recurrence of calculi is a major problem. Open surgical techniques are indicated in the case of large stones. Both patients underwent ESWL and it was successful in our first case. The second patient had also undergone pyelolithotomy seven years prior to the diagnosis of PH 1.

Management of PH after onset of ESRD is conservative with haemo or peritoneal dialysis. There may be a place for liver transplantation prior to onset of ESRD as AGT is produced in the liver. Isolated kidney transplantation does not help as the disease recurs in the transplanted kidney. Combined liver kidney transplantation has been shown to be the only way to replace both the biochemically defective organ (liver) and the pathophysiologically damaged organ (kidney) in patients with $\mathrm{ESRD}^{4}$. In an ideal world, our second patient would have been offered this treatment.

The prognosis of untreated $\mathrm{PH}$ is poor leading to death around the age of 20 years. Hence the aim of management, especially in the developing world, should be early diagnosis and adequate treatment.

These two cases reiterate the importance of investigating children with urolithiasis, to identify the aetiology. It also highlights the fact that this is possible to a significant extent, if our limited resources are appropriately used.

\section{Acknowledgements}

We thank Dr Mrs M Gunathillake, Consultant Chemical Pathologist, Medical Research Institute, Colombo and Dr N D Perera, Consultant Urologist, National Hospital, Colombo for there valuable help in management of these patients.

\section{References}

1. Coward R J M, Peters C J, Duffy P G et al. Epidemiology of paediatric renal stone disease in the UK Archives of Disease in Childhood 2003; 88:962-5.

2. Hulton S A. Evaluation of urinary calculi in children. Archives of Disease in Childhood 2001; 84: $320-3$.

3. Danupre $\mathrm{C}$ J. Recent advances in the understanding diagnosis and treatment of primary hyperoxaluria type 1 . J Inher Met Dis 1989; 12: 210-24.

4. Cochat P, Basmaison O. Current approaches to the management of primary hyperoxaluria Archives of Dieases in Childhood 2000; 82:4703

5. Johnson S A, Rumsby G, Cregeen D, Hulton S A. Primary hyperoxaluria type 2 in children. Paediatr Nephrol 2002; 17(8): 597-601. 